\title{
Earnings Of Hispanic And Asian Immigrants: Are Hispanic Immigrants Discriminated Against?
}

\author{
Jongsung Kim, (Email: jkim@bryant.edu), Bryant College
}

\begin{abstract}
The heterogeneity of immigrants raises a question as to whether there is a general pattern of earnings progress that applies to all immigrants. As there are many types of immigrants, earnings patterns among immigrant groups are not well known. To fill in this research gap, this paper investigates the role of various determinants in the earnings process of two major immigrant groups: Hispanic and Asian immigrants. If there is a gap between these two immigrant groups, could it be a result of different human capital characteristics or some other factors? According to empirical results based on the 1990 Census of Population 5 percent Public Use Microdata Sample (PUMS), the decomposition of the earnings difference between immigrant groups indicates that approximately 28 percent of the gap is unexplained by the observable labor market characteristics. Cotton's modified version of the Oaxaca-Blinder procedure is used to decompose the earnings gap.
\end{abstract}

\section{Introduction}

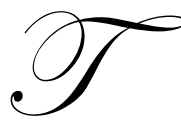

he slowly but steadily changing composition of immigrants in the U.S. during the last few decades has forced researchers to reevaluate classical assimilation theory. Many researchers today are skeptical of the ability of some immigrant groups and their offspring to go through same educational and occupational channels that white immigrants did in order to achieve economic parity with white Americans. Some economists argue that the inability of new immigrants to readily adapt to the U.S. economy is directly related to changes in the quality of immigrant. Many scholars recognize that recent immigrants may have more difficulty gaining good jobs in the U.S. labor market because they lack the job experience, education, and training necessary to compete with native workers (Borjas, 1985).

Assimilation theory follows that the earnings of immigrants usually increases with the passage of time as they acquire more human capital necessary for the economic success in the country of destination, while immigrants tend to be disadvantaged economically in the initial stage of arrival. However, the heterogeneity of immigrants raises a question as to whether there is a general pattern of earnings that applies to all immigrants. As there are many types of immigrants, earnings patterns among immigrant groups are not well known. To fill in this research gap, this paper supplements the existing literature by investigating the role of various determinants on the earnings process of different immigrant groups, particularly Hispanic and Asian immigrants, and addresses the following question. If there is a gap across different immigrant groups, could it be a result of different human capital characteristics or some other factors?

The number of immigrants living in the United States has more than tripled since 1970, from 9.6 million to 28.4 million. As a percentage of the U.S. population, immigrants have more than doubled, from 4.7 percent in 1970 to 10.4 percent in 2000. In addition to this, the 8.6 million increase in the size of the immigrant population between 1990 and 2000 is equal to approximately one-third of total U.S. population growth over this period (Camarota, 2001). Although it is hard to predict precisely, a recent Census projection provides some indication about the trend

Readers with comments or questions are encouraged to contact the author via email. of immigrant population. Between 2000 and 2100, under the Census Bureau U.S. Population projection's middle 
series, the non-Hispanic white percentage of the U.S. population will decline from 72 percent to 40 percent and will continue to fall after 2100. In younger age cohorts, non-Hispanic whites will comprise an even smaller percentage of the population. In contrast, the Hispanic share will jump from 12 percent to 32 percent (and continue to rise), Asian from 4 percent to 13 percent, and non-Hispanic blacks from 13 percent to 15 percent. Amazingly, as recent as the 1980 Census, Hispanics and Asian together accounted for only 8 percent of the population (U.S. Census Bureau, 2000)

For reasons of size and rapid growth alone, the Hispanic population would deserve the attention of policy makers and analysts. The Hispanic population grew by 53 percent during the 1980s and then by another 27 percent between 1990 and 1996. If Census Bureau projections are correct, by 2020 Hispanics will number 52 million persons and 16.3 percent of the population, and by 2050 they will number 97 million persons and constitute 24.5 percent of the U.S. population, thereby replacing blacks to be the first minority group. Although the number is much less impressive, the number of U.S. population of Asian decent has been also increasing. Between 1981 and 1998 nearly 15 million legal immigrants came to America. Some 4.75 million of these were Asians, a little over 30 percent of the total. This dramatic change from the conditions of exclusion or near exclusion that existed earlier in this century reflects a basic change in American society. Asian Americans are currently the fastest-growing ethnic group in the U.S. Their population growth of 37 percent between 1990 and 1998 was the highest of any race or ethnic group (Kitano and Daniels, 2001). Asian Americans have often been labeled as the "model minority," for successful economic assimilation. To the extent that this is true, Asian immigrants may be better treated than immigrants of other ethnicities. Does the U.S. labor market prefer Asian immigrants to equally qualified Hispanic immigrants? This paper addresses this question and measures the extent to which Hispanic immigrants are discriminated against in the U.S. labor market.

\section{Immigrants' earnings}

The debate on the immigration has pitted economists, policy-makers and politicians who are in favor of immigration against those who are skeptical of the contribution of immigrants to the U.S. The absence of the consensus on this issue is the proof that it is extremely complicated to pinpoint whether or not the immigration is beneficial to the U.S. economy. Research on the earnings of immigrants has been mainly focusing on the immigrants' ability of assimilation into American society. While it is hard to find a definition of assimilation that can be applied to all aspects of life, economic assimilation is achieved when immigrants have the same economic opportunities as native-born workers, and the returns to human capital investments are same for both groups.

Using the 1970 U.S. Census and Mincer-type human capital earnings function, Chiswick (1978) found that the earnings of the foreign-born of that era eventually exceeded those of similar persons born in the United States. However, he found that the U.S. earnings of Mexican-born workers are lower than those of other foreign-born workers. In the last decade, Borjas (1985) repudiated not only the conclusion about earnings convergence offered by Chiswick but also its entire empirical foundation. His primary criticism is that using single cross-section data is not an appropriate method of identifying cohorts and the aging effect, and further confounds the assimilation effect and the cohort effect. Borjas offers his own evidence that the earnings of more recent immigrant cohorts are not converging on the earnings of their U.S.-born counterparts. While it is well known that there is a substantial gap in earnings and occupational status between natives and immigrants, those gaps across different immigrant groups are not well known. Likewise, differences in returns to education, age, and experiences that account for a large fraction of earnings gap between natives and immigrants are expected to display different patterns across different immigrant groups.

\section{Data and variables}

The most recent, reliable, large data set with sufficient number of immigrants that permits an analysis of immigrants in the U.S. labor market is the 1990 Census of Population. The 5 percent Public Use Microdata Sample (PUMS) of the 1990 U.S. Censuses of Population and Housing was used for this study. Hispanic and Asian immigrant sample is identified in the 1990 census by the questions on Hispanic ancestry, race and the place of birth.

Persons aged 25 to 64 years are considered due to the focus on the labor market. The age restriction is in- 
troduced to exclude the aged, most of whom have retired from the labor market; and the young, who are still attending school and the early years of on-the-job training. As members of the armed forces receive much of their compensation in kind (subsidized food, housing, medical care) rather than cash, the inclusion of the member of armed forces may bias estimates of the effect on total earnings (Chiswick, 1983). For this reason they have been deleted from the sample. The final sample includes 84,346 Asian immigrants who satisfy the sample selection criteria, identified themselves of Asian race and were born in one of the following Asian countries: China $(19,673)$, Korea $(13,121)$, India $(12,778)$, Vietnam (11,001), and the Philippines $(27,773)$. In the final sample are 122,525 Hispanic immigrants that satisfy the sample selection criteria, identified themselves of Hispanic race and were born in one of the following countries: Mexico $(94,776)$, Puerto Rico ${ }^{1}(21,392)$, and Dominican Republic $(6,357)$.

Variables chosen for the empirical analysis are divided into the following categories. The natural logarithm of the yearly earnings is used as the dependent variable. First group of control variables includes human capital characteristics: education, experience, and the English language proficiency. The human capital theory views the acquisition of skills and knowledge as investments of resources on people for future economic payoffs. Such skills and knowledge are supposed to increase worker productivity that will eventually be translated into socioeconomic rewards. However, returns to education are known to vary across immigrant groups. While underemployment and job-mismatch are found among the highly educated, education improves the economic situation of workers through better jobs and wages. English language proficiency is another important factor in determining the earnings of immigrants. The lack of English language proficiency reduces the income and affects occupational opportunities negatively (Koussoudji, 1988). Second group of variables includes the location and occupation characteristics. Geographic variable "South" is included to control for the lower income status of southern states. It is well documented that as immigrants assimilate in the U.S., the level of earnings increases. Therefore, "Years Since Migration" is expected to report a positive impact on earnings. While Asians are generally regarded as a model minority who are better off than other ethnic groups in the U.S., this notion has been challenged recently. Masked in the notion of economic success may be types of occupations that require longer hours of labor. In order to control for this, "hours of work (annual)" is included.

\section{Empirical model and estimation}

The earlier econometric literature addressed the issue of earnings differentials by estimating one earnings function that incorporates productivity-related variables as explanatory variables and a dummy variable for ethnicity. Therefore, if the estimated coefficient of the ethnicity variable is significantly different from zero, the earnings differential between two groups in question is considered to be statistically significant. However, the implicit assumption lies in this method is that all the estimated coefficients are identically applied to both groups, which is unreasonable in most cases. In an effort to overcome this shortcoming, and to take into account wage differentials brought about by different endowments between different ethnic groups, this paper adopts the method introduced by Oaxaca (1973) and Blinder (1973). This method estimates separate semi-log earnings functions for two groups and measures the relative importance of sources of wage differences. The Blinder-Oaxaca method allows separating the wage differentials into skills and treatment components, and has been widely used in labor market studies, especially on racial and gender earnings gap.

In this paper, the econometric method just described is applied to the sample of Hispanic and Asian immigrants to measure the earnings differential that stems from different sources. The differences in the distribution of Hispanic and Asian immigrants across the human capital categories captures the portion of the wage gap accounted for by differences in endowments. Some or all of this portion is considered to arise from non-market discrimination. The standard Blinder-Oaxaca decomposition method implicitly assumes that the wage of advantaged group is the wage that the disadvantaged group would have in the absence of discrimination and expresses the difference between the mean log earnings of Hispanic and Asian immigrants as:

$$
\begin{aligned}
& \ln \mathrm{W}^{\mathrm{A}}=\beta_{j}^{A} X_{j}^{A}+\varepsilon_{A} \\
& \ln \mathrm{W}^{\mathrm{H}}=\beta_{j}^{H} X_{j}^{H}+\varepsilon_{H}
\end{aligned}
$$

where the superscript $\mathrm{A}$ and $\mathrm{H}$ stand for Asian and Hispanic immigrants, $\mathrm{W}$ is earnings, the vector $\mathrm{Xs}$ 
represent human capital endowments, and the estimated coefficients $(\beta s)$ represent the returns in the labor market to human capital. $\varepsilon s$ are disturbance terms. The Chow test of equality between the two sets of estimated coefficients between Hispanic and Asian immigrants' earnings equations is highly significant, thereby rejecting the null hypothesis of equivalent coefficients to justify the use of separate earnings equations for the two groups. In this method, the current earnings of one of the two groups is used as the earnings level in the absence of discrimination. Therefore, it follows that

$$
\ln \overline{\mathrm{W}}^{\mathrm{A}}-\ln \overline{\mathrm{W}}^{\mathrm{H}}=\beta_{j}^{A} \bar{X}_{j}^{A}-\quad \beta_{j}^{H} \bar{X}_{j}^{H}
$$

where the $\overline{\mathrm{W}}$ and $\overline{\mathrm{X}}$ s represent mean earnings and mean human capital endowments, respectively. To further analyze the earnings difference between Hispanic and Asian immigrants, a decomposition analysis is conducted as follows.

$$
\begin{aligned}
& \ln \overline{\mathrm{W}}^{\mathrm{A}}-\ln \overline{\mathrm{W}}^{\mathrm{H}}=\sum \beta_{j}^{A}\left(\bar{X}_{j}^{A}-\bar{X}_{j}^{H}\right)+\sum \bar{X}_{j}^{H}\left(\beta_{j}^{A}-\beta_{j}^{H}\right) \quad \text { or } \\
& \ln \overline{\mathrm{W}}^{\mathrm{A}}-\ln \overline{\mathrm{W}}^{\mathrm{H}}=\beta_{j}^{H}\left(\bar{X}_{j}^{A}-\bar{X}_{j}^{H}\right)+\bar{X}_{j}^{A}\left(\beta_{j}^{A}-\beta_{j}^{H}\right)
\end{aligned}
$$

One can decompose the wage differentials using either Hispanic or Asian immigrants' human capital endowments as the base; there is no advantage in selecting one or the other equation. The first term on the right-hand side of (4) and (5) are estimates that are part of the wage differential due to differences in productivity based on the differing endowments of observable earnings characteristics such as schooling and experience, and the second terms are associated with labor market treatment of the workers' observable and unobservable characteristics or discrimination component. While many studies on racial earnings differentials assume that the wage structure that would prevail in the absence of discrimination was more likely to be close to the white wage function than to the wage function of blacks, and prefer one form to other, in the present study there is no a priory reason to prefer one ethnic group to another.

Cotton's method improves the original method of the traditional Blinder-Oaxaca decomposition technique. Cotton (1988) observed that using either the majority's or minority's coefficients as nondiscriminatory wage structure is flawed by writing " ... not only is the group discriminated against undervalued, but the preferred group is overvalued, and the undervaluation of the one subsidizes the overvaluation of the other." Cotton further suggested the following decomposition technique that is based on the weighted average of the coefficient for the two groups. ${ }^{2}$ The decomposition then can be written as:

$$
\ln \overline{\mathrm{W}}^{\mathrm{A}}-\ln \overline{\mathrm{W}}^{\mathrm{H}}=\sum \beta_{j}^{*}\left(\bar{X}_{j}^{A}-\bar{X}_{j}^{H}\right)+\sum \bar{X}_{j}^{A}\left(\beta_{j}^{A}-\beta_{j}^{*}\right)+\sum \bar{X}_{j}^{H}\left(\beta_{j}^{*}-\beta_{j}^{H}\right)
$$

where $\beta^{*}=\mathrm{p}_{\mathrm{A}} \beta^{A}+\mathrm{p}_{\mathrm{H}} \beta^{H}$, and $\mathrm{p}_{\mathrm{A}}$ and $\mathrm{p}_{\mathrm{H}}$ are the proportions of Asian immigrants and Hispanic immigrants, respectively. In this decomposition the treatment or discrimination component is made up of two elements, one representing the amount by which productivity characteristics of more preferred group (Asian) are overvalued (the "benefit" of being a more preferred group worker), and the other representing the amount by which productivity characteristics of less preferred groups are undervalued (the cost of being a less preferred group worker).

\section{Estimation results}

Summary statistics clearly conveys that the two groups are quite different in their earnings structure. The Asians acquired more formal schooling, while the years of labor market experience of Hispanic immigrants exceed that of Asian immigrants by approximately 10 percent. The Asian immigrants are more likely to be married and they show a smaller degree of concentration in South. It is no surprise to find more Asians in managerial occupations and less in craft or operator occupations. On average, Asian immigrants worked about one month longer than Hispanic immigrants in 1989. In both groups, men are found to earn more than women. 
There is a considerable earnings differential between Hispanic immigrants and Asian immigrants: Hispanic immigrants on average earn $\$ 15,272$ or 42 percent less than Asian immigrants. While these numbers suggest that one group is economically better than the other, simple comparisons of the average income do not reveal the extent to which individual characteristics such as human capital, and occupation contribute to earnings. Therefore, it is still important to investigate the causes of the earnings differences and to look at whether the process governing earnings gap differs across different ethnic groups.

Table 1 lists the estimated coefficient of earnings equation along with the means of variables. Although the results of the empirical analysis indicate that there are substantial differences in earnings patterns between two groups, almost all of the estimated coefficients conform to theoretical expectations. The labor market treats most of the observable productivity-related characteristics of both immigrant groups favorably. The major portion of earnings advantage of Asian immigrants is ascribed to observable characteristics. While the English language proficiency is expected to improve with the passage of time, the lack of English proficiency is more detrimental to Hispanic immigrants than to Asians. Significantly positive effects of English language proficiency is understandable considering that most of jobs that command higher pay requires good communication skills. The earnings disadvantage of those in South is observed in both groups of immigrants.

Table 1. Earnings equation estimates and Means of variables

\begin{tabular}{l|ll|ll}
\hline \multirow{2}{*}{ Variable } & \multicolumn{2}{|c}{ Hispanic immigrants } & \multicolumn{2}{c}{ Asian immigrants } \\
\cline { 2 - 5 } & Estimate & Mean & & Mean \\
Ln (Earnings) & & & & 9.751 \\
Constant & 7.32 & 9.276 & 7.30 & \\
Schooling & .027 & 7.2 & .04 & 11.9 \\
Experience & .02 & 22.9 & .02 & 20.2 \\
Experience & -.0002 & 524.4 & -.0004 & 408 \\
Sex & -.337 & .36 & -.248 & .48 \\
Married & .087 & .70 & .049 & .79 \\
English & .122 & .54 & .15 & .75 \\
South & -.216 & .24 & -.124 & .18 \\
Managerial & .509 & .08 & .535 & .32 \\
Technical & .267 & .14 & .211 & .31 \\
Service & .108 & .46 & $.058^{*}$ & .24 \\
Operator & .207 & .32 & $.102 *$ & .13 \\
Hour & .001 & 1753.3 & .001 & 1909.3 \\
YSM & .01 & 15.8 & .02 & 11.9 \\
& & & & \\
$\mathrm{~N}$ & 122,525 & & .475 & \\
Adjusted $\mathrm{R}^{2}$ & .473 & & & \\
& & & & \\
\hline
\end{tabular}

Notes: * denotes not significance at 5 percent level. All other estimated coefficients are statistically significant at 1 or 5 percent level. English $=0$ if ability to speak English is marked as either "not well" or "not at all."

Table 2 shows decomposition of the log earnings difference between Hispanic and Asian immigrants using the model described in the previous section. The difference in log earnings of .474 translates to a very significant earnings gap. Average earnings of Hispanic immigrants is $\$ 15,272$, which is only 58 percent of $\$ 26,210$, the average earnings of Asian immigrants. According to Table 2, about 72 percent of this earnings gap is accounted for by the differences in the endowed observable characteristics between the two groups. Actually, almost all of the Asian 
immigrants' earnings advantage is due to higher education and a greater number of weeks worked. The remaining 28 percent are due to unobservable characteristics or labor market discrimination.

Table 2. Decomposition of earnings gap

Mean Difference in Log Earnings $=.474$

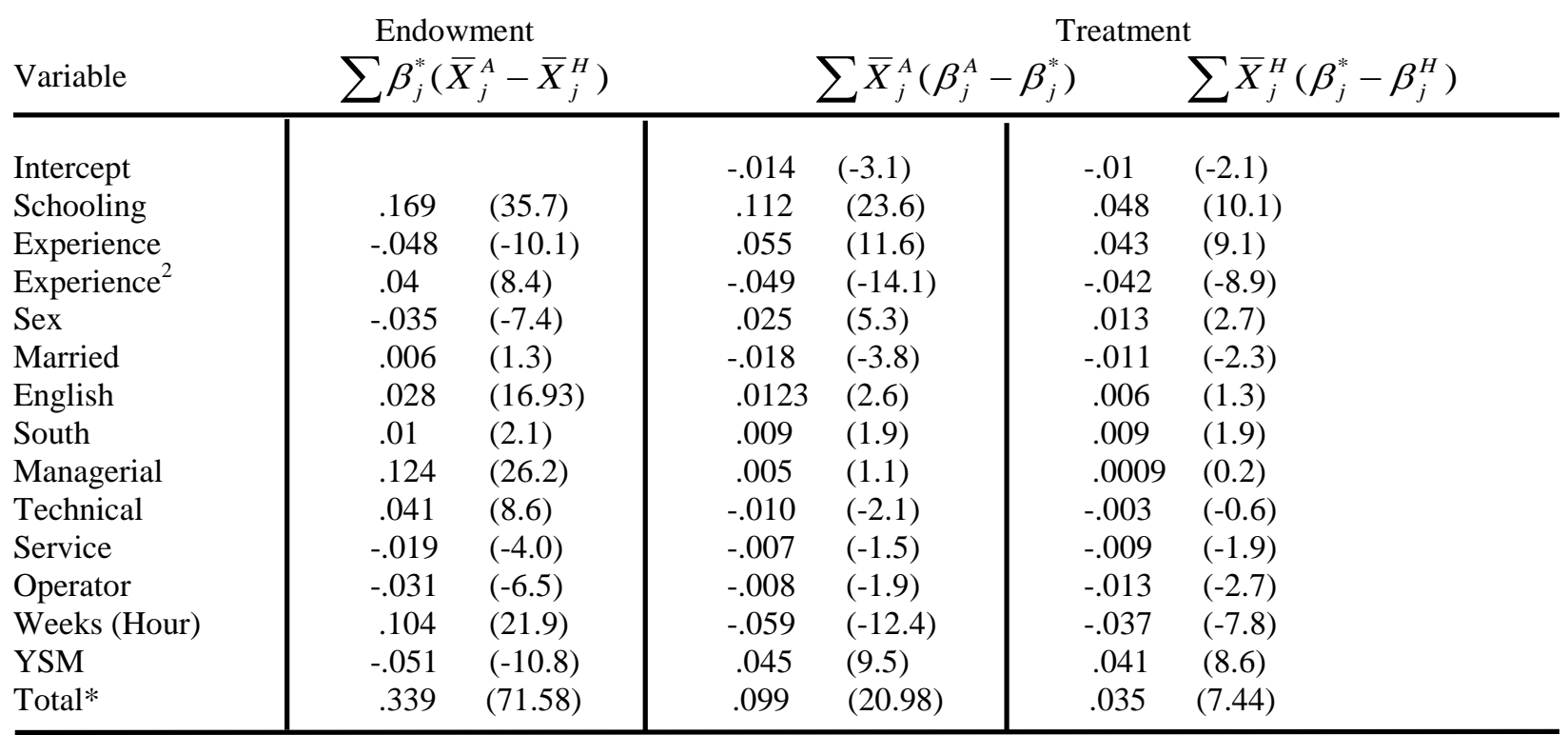

Notes: * Total may not equal to 1 due to rounding. Figures in parentheses are percentages. All numbers are significant at 5 percent level.

\section{Conclusion}

This research examines income determination processes of Hispanic and Asian immigrants. It was found that while both Hispanic and Asian immigrants are foreign born, there are remarkable differences in their characteristics in addition to ethnicity. We found rather big earnings gap between Hispanic and Asian immigrants, and ethnicity is less important than human capital characteristics in explaining the earnings gap between Hispanic and Asian immigrants. Asian immigrants' greater returns to their human capital explain a large proportion of the earnings gap.

The decomposition of the earnings difference between Asian immigrants and Hispanic immigrants indicates that 28 percent of the earnings gap is unexplained by the observable labor market characteristics. Most of the observable human capital endowments of Hispanic immigrants are treated unfavorably by the market compared to those of Asian immigrants. The earnings disadvantage of immigrants attributable to unobserved factors exacerbates the Hispanic immigrants' disadvantage even more. It is unclear whether the unobserved factors actually enhance the productivity of Asian immigrants or are simply a result of the market's preferential treatment of Asian immigrants based on the notion that they are more productive due to the notion of model minority. Although this is quite a suggestive finding about the role of human capital characteristics and other factors in the earnings of Hispanic and Asian immigrants, the exact nature of the unobserved characteristics and their functions remain to be studied.

\section{Endnotes}

1. Although persons born in Puerto Rico are U.S. citizens and thus are technically natives, they are born into a 
linguistic and cultural environment that is closer to that of Hispanic immigrants than it is to that of Hispanics born on the mainland (Chiswick and Hurst, 2000). Purely for the purpose of simplicity of exposition, persons born in Puerto Rico are referred to as immigrants throughout this paper.

2. Reimers (1983) also observed this point, but suggested the arbitrary use of 0.5 to provide a weight.

\section{References}

1. Blinder, Alan S. 1973. "Wage Discrimination: Reduced Form and Structural Estimates," Journal of Human Resources 8, 436-55.

2. Borjas, George J. 1985. "Assimilation, Changes in Cohort Quality, and the earnings of Immigrants," Journal of Labor Economics 3, 463-489.

3. Camarota, Steven A. 2001. Immigrants in the United States--2000 A Snapshot of America's Foreign-Born Population, Center for Immigration Studies.

4. $\quad$ Chiswick, Barry R. 1986. "Is the New Immigrant Less Skilled than the Old?" Journal of Labor Economics 4, 168-92.

5. _. 1983. "An analysis of the earnings and employment of Asian-American men," Journal of Labor Economics 1, 197-214.

6. $\quad$ and Michael Hurst. 2000. "Hispanics and the American Labor Market." In Hispanics in the United Sates, edited by Pastora Cafferty and David Engstrom, 175-193, Transaction Publishers.

7. Cotton, Jeremiah. 1988. "On Decomposition of Wage Differential," Review of Economics and Statistics 70. 235-43.

8. Daniels, Roger, and Otis L. Graham. 2001. Debating American Immigration, 1882 - Present. Rowman \& Littlefield Publishers, Inc.

9. Kitano, Harry H.L. and Roger Daniels. 2001. Asian Americans: Emerging Minorities (3 ${ }^{\text {rd }}$ edition). Prentice Hall.

10. Kossoudji, Sherrie. 1988. "English language ability and the labor market opportunities of Hispanic and East Asian Immigrant Men." Journal of Labor Economics 6, 205 -228.

11. Oaxaca, Ronald. 1973. "Male-Female Wage Differentials in Urban labor markets," International Economic Review 14, 683-709.

12. Reimers, Cordelia W. 1983. "Labor Market Discrimination Against Hispanic and Black Men," The Review of Economics and Statistics 65, 570-579.

13. U.S. Census Bureau. 2000. Population Division Working Paper No. 38. (http://www.census.gov/population/www/projdections/natproj.html)

Notes 
